\title{
HANDS-ON \\ WORD PROCESSING
}

\section{Peter Flewitt}

\author{
(C) Peter Flewitt 1984
}

All rights reserved. No part of this publication may be reproduced or transmitted, in any form or by any means, without permission.

First published 1984 by

THE MACMILLAN PRESS LTD

London and Basingstoke

Companies and representatives

throughout the world

\author{
ISBN 978-0-333-36185-6 ISBN 978-1-349-06974-3 (eBook) \\ DOI 10.1007/978-1-349-06974-3
}

Typeset in Great Britain by

Type Generation Ltd, London EC1. 


\section{Welcome to Hands-On Word Processing}

This Course is intended for students having a basic keyboard knowledge to at least RSA I standard or equivalent who now wish to progress towards an understanding of word-processing techniques. On completion of the course, including the set exercises and the number of hours of hands-on experience required by the examining bodies, the student should possess the standard of competence required for B/TEC National Word Processing; RSA Word Processing Stage I; RSA Information Processing; LCCI Word Processing; LCCI Information Processing; Pitman Practical Word Processing; Pitman WP Theory and Practice, examinations at a similar level, and the word-processing content of most Group Secretarial Syllabuses and examinations.

As all word processors and microcomputers with word-processing packages differ in operation, it has not been possible to include specific instruction regarding the keys to be struck to perform the various operations. Space has been provided for you to write in the keystrokes relating to the particular equipment in use, following instruction from your teacher, or reference to the machine's manual.

The order in which certain operations are carried out will also vary from one make or type of machine to another. For example, you may need to open a file before or after the text is typed. For this reason, and for ease of reference, the operations have been grouped under seven main headings, to which you may refer easily for revision. The Contents page is designed to act as a check-list against which you may tick off each exercise as it is completed, in the box provided.

As far as possible, the exercises have been designed to be achievable on most types of machine, though the ease or otherwise of performing them will necessarily vary from one machine to another. Some operations may not be possible on the more basic types of word processors, or on some microcomputer word-processing packages. Where an operation is found to be impracticable for this reason, ensure that you are shown, or have explained to you, how it can be done on other machines.

Basic procedures for safety should be observed at all times, and great care exercised in the handling of equipment, program software and work-disks. Repairs and replacements can be extremely costly, and 'down-time' can deprive you and others of valuable hands-on-time.

IF IN DOUBT, ASK!

Now turn to page 4, and read 'How to Use this Workbook'. 


\section{Setting up the Video Page}

1 Setting margins

2 Setting and clearing tabs

3 Setting align or decimal tabs

4 Setting or changing line spacing

5 Setting or changing pitch

6 Setting or changing page width

7 Setting or changing page length

8 Setting or changing lines per page

9 Clearing the screen

\section{Keying in Text}

1 The cursor

2 Correcting mis-hit characters

3 Erasing characters

4 Deleting characters

5 Inserting characters

6 Inserting space

7 Typing to align tabs

8 Centring text

9 Underlining text

10 Indenting to tabs

11 Typing records

\section{Editing Text}

1 Erasing blocks of text

2 Deleting blocks of text

3 Underlining blocks of text

4 Erasing underlining

5 Reformatting text

6 Moving text within a page

7 Moving text from page to page

\section{Filing}

1 Opening a file

2 Recalling text to the screen

3 Leaving a document

4 Updating a file

5 Deleting a file

6 Duplicating a file

7 Duplicating a disk

8 'Dustbin' files

9 Pagination

10 Headers and footers

\section{Printing}

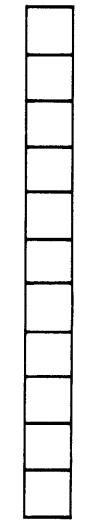

1 Printing from the screen

2 Printing from storage

3 Print options

(i) Above option

(ii) Below option

(iii) Codes option

(iv) Blocks option

(v) Justify option

(vii) Emboldening text

4 Changing line spacing within a page

5 Changing pitch within a page

\section{Composite Documents}

1 Standard letters

(i) Typing in variables on the screen

(ii) Merging the letter

(iii) Merging the variables

2 Envelopes and labels

3 Form-filling

4 Non-linear merge

5 Creating the standard page

6 The grid

7 Mode or direct print

8 Alternative variables page

9 Merging to the alternative variables page

10 Standard paragraphs

\section{Special Features}

1 Locate

2 Search \& replace

3 Sort

4 Graphics

5 The library or vocabulary function

6 Spelling verification

7 Maths

8 Special characters 


\section{How to Use this Workbook}

Different makes and types of word processors or computer will require the various functions and operations to be taught in different order.

On some machines, for example, it is necessary to open a file before one can begin to type; on others the text may be typed first, and the file opened when the page is completed. Ease or otherwise of performing certain functions may render them elementary practice on some machines, but find them requiring a fairly advanced knowledge on others.

A set of plancards, each relating to a single exercise in the Student's Workbook, is supplied with the Teacher's Book to this course. These enable the teacher to devise a suitable plan of work for any make or type of word processor.

When the plancards have been sorted by your teacher, they will indicate a suitable order in which the exercises should be carried out on the particular word processor which you are using. Keep strictly to this order unless your teacher tells you differently. The sequence of exercises takes account of which operations need to have been carried out previously in order to do every exercise. Deviating from the planned sequence may mean that you find yourself being asked to do things which you have not yet learned.

If you find yourself in difficulty, ask! 